\title{
Effect of Roughness on Discharge
}

\author{
T.W. Lau, and N.R. Afshar
}

\begin{abstract}
These Water resource projects and hydraulic engineering works have been developing rapidly throughout the world, thus prediction of water roughness coefficient is becoming an importance criteria for the designs of hydraulic related structure like open channel, and dam structure. The purposes of this research are to determine the effect of roughness on discharge and study on the factors that affect roughness coefficient. The roughness coefficient for this study is expressed in terms of Manning's $n$. Experimental works were carried out to study the effect of roughness by using flumes $(8 \mathrm{~m} \times 0.3 \mathrm{~m} \times 0.4 \mathrm{~m})$ with different types of roughened bed such as $2 \mathrm{~mm}$ grain size plate and $5 \mathrm{~mm}$ grain size plate. The experiments were being tested with various flow rates for slope equal to 1:300, 1:600 and 1:900 to determine the effect of slope on roughness coefficient. The results of the experimental study were presented and shown that the effect of surface roughness, material grain size, channel slope, and Manning's roughness coefficient on flow rate. For the range of conditions tested, the discharge was found to be decreased as roughness coefficient increase. From the experiments, it shows smoother surface is having lower roughness coefficient and less retarding effect on the water flow, higher flow rate is produced. As conclusion, flow rate and roughness coefficient were influenced by bed roughness and slope.
\end{abstract}

Keywords: Roughness, Uniform Flow, Manning Equation and Channel Slope

\section{INTRODUCTION}

$I^{2}$ $\mathrm{N}$ recent years, water resource projects and hydraulic engineering works have been developing rapidly throughout the world. The knowledge of open channel hydraulic is essential for every engineer when come to the hydraulic structure design.

Flows in open channel are categorized into two classes which are steady flow and unsteady flow. Also, the steady flow is subdivided into uniform flow and varied flow. The concept of uniform flow is central to the understanding and solution of most problems in open channel hydraulic [1]. Generally, all water channels, lying from natural stream beds to lined artificial channels, exhibit unique or distinctive coefficient of roughness depend on the condition of the channel. Coefficient of roughness, $n$, is defined as a parameter representing the channel roughness and flow resistance. Previous study has identified several significant factors that affecting the velocity in a given channel such as water area, maximum surface velocity, wetted perimeter, maximum depth, slope of water surface, coefficient of roughness, and temperature of water. Manning Equation has been identified as the most appropriate formulae to represent the open channel flow application [2].

Roughness coefficients represent as a very importance parameter when come to the computation of discharge or capacity of waterway, storm water drainage system, canal, flow in conduit pipe, etc [3]. The factors affecting Manning's roughness coefficient are cross sectional geometry and boundary roughness surface roughness, vegetation on channel [4], channel irregularity [3], channel alignment, silting and scouring, obstruction, size and shape of channel, stage and discharge, seasonal change, and suspended material and bed load.

In recent years, many researches have been conducted regarding the coefficient of roughness all over the world. However, there are still many uncertainness remains concerning the effect and determine the precise value of channel roughness coefficient for computation of discharge for open channel hydraulics.

\section{Flow Resistance EQuATION}

Manning Roughness coefficients $\mathrm{n}$ represent the resistance to flood flows in channels and flood plains. Flow resistance is defined as "the force to overcome or the work required to be done to counter the action of the rigid, flexible, or moving boundary on the flow" [5]. The results of Manning's formula, an indirect computation of stream flow, have applications in flood-plain management, flood insurance studies, and the design of bridges and highways which across flood plains. The Manning's' roughness coefficient of the bed (n), was calculate by rearranging the Manning Formula [1] into [2] i.e

T.W.Lau was with the Department of Civil Engineering, Faculty of Engineering, Universiti Malaysia Sarawak, 94300 Kota Samarahan, Sarawak, Malaysia.

Assoc. Prof. Dr Nasser Rostam Afshar is with the Department of Civil Engineering, Faculty of Engineering, Universiti Malaysia Sarawak, 94300 Kota Samarahan, Sarawak, Malaysia (e-mail: anrostam@feng.unimas.my). 


$$
\begin{array}{ll}
\text { rearrange } & V=\frac{1}{m} R^{2 / a} S^{1 / 2} \\
\text { into } & n=\frac{1}{V} R^{2 / a} S^{1 / 2}
\end{array}
$$

Where $\mathrm{V}$ is the velocity in $\mathrm{m} / \mathrm{s}, \mathrm{R}$ is the hydraulic radius in $\mathrm{m}, \mathrm{S}$ is the slope, and $\mathrm{n}$ is the Manning's roughness coefficient.

\section{LABORATORY WORKS}

The experimental study included three type of bed roughness, namely smooth surface (steel plate), and rough surface ( $2 \mathrm{~mm}$ and $5 \mathrm{~mm}$ grain size gravel respectively). The first sets of experiments (smooth surface) were conducted without putting any roughness plate on the flow channel and were repeated for channel slope equal to 1:300, 1:600, and 1:900.

Experiments for rough surface were conducted with plate NO.1 and plate NO.2 respectively, each of the plate had its own value of roughness height, to study the effect of roughness element on flow resistance. Further details of experimental conditions are described in Table 1.

Table 1: Experiments conditions

\begin{tabular}{crl}
\hline Slope & Test & \multicolumn{1}{c}{ Bed Surface } \\
\hline \multirow{3}{*}{$1: 300$} & 1 & Smooth \\
& 2 & 2 mm grains size \\
& 3 & 5 mm grains size \\
\hline \multirow{3}{*}{$1: 600$} & 4 & Smooth \\
& 5 & 2 mm grains size \\
& 6 & 5 mm grains size \\
\hline \multirow{3}{*}{$1: 900$} & 7 & Smooth \\
& 8 & 2 mm grains size \\
& 9 & 5 mm grains size \\
\hline
\end{tabular}

\section{RESULTS AND DISCUSSION}

\subsection{Effect of Different Type of Bed material on Roughness Coefficient}

Test 1, 4 and 7 with smooth roughness have been analyzed to determine the relationship between the bed roughness and roughness coefficient for a steeper slope of (1:300)

Figure 1 indicates those roughness coefficients are mostly constant throughout the experiments when tested with different flow rate. For example, the different between the maximum value, 0.0190 and minimum value, 0.0180 of Manning's for test 1 (rougher gravel surface) is only 0.0010 which is small or can be said remain constant along the experiment conducted. Similar results were observed from the other tests which stated roughness coefficient Manning's n will not vary through increased water discharge.

From Figure 1, it was observed that bed roughness have effect on Manning's roughness coefficient and flow rate. For example, test 1 was conducted with smooth surface which having a lower roughness coefficient compare to test 2 (2 mm grain size rough surface), and test 3 (5 mm grain size rough surface). It may be concluded that every type of surface has their specific roughness coefficient and the rougher the surface is, the higher the roughness coefficient will be. The average and range of Manning roughness coefficient of each steel plate has been tabulated in Table 2 for slope equal to 1:300.

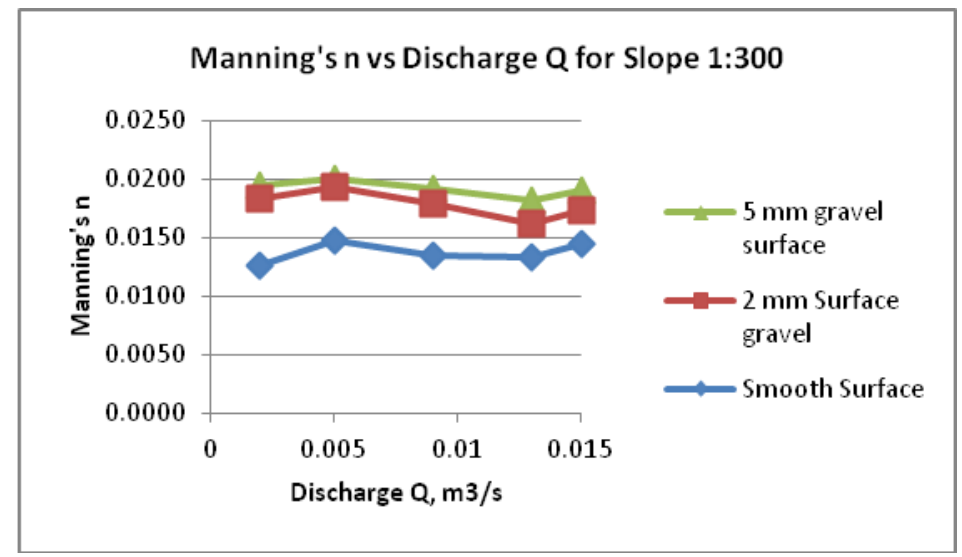

Figure 1: Manning's n versus Discharge Q for Slope 1:300 
UNIMAS e-Journal of Civil Engineering: Volume 4, Issue 3

Table 2: Average Roughness Coefficient of Different Surface for Slope 1:300

\begin{tabular}{|c|c|c|c|c|c|c|c|}
\hline \multirow{2}{*}{ Bed Surface (Plate) } & \multicolumn{5}{|c|}{ Discharge $\mathrm{Q}\left(\mathrm{m}^{3} / \mathrm{s}\right)$} & \multirow{2}{*}{ Average $n$} & \multirow{2}{*}{ Range of $n$} \\
\hline & 0.002 & 0.005 & 0.009 & 0.013 & 0.015 & & \\
\hline Steel & 0.0126 & 0.0148 & 0.0135 & 0.0133 & 0.0144 & 0.0137 & $0.0133-0.0148$ \\
\hline $2 \mathrm{~mm}$ Grain size & 0.0183 & 0.0193 & 0.0178 & 0.0161 & 0.0172 & 0.0177 & $0.0161-0.0193$ \\
\hline $5 \mathrm{~mm}$ Grain size & 0.0194 & 0.0200 & 0.0191 & 0.0181 & 0.0191 & 0.0191 & $0.0181-0.0200$ \\
\hline
\end{tabular}

The result of test 2, test 5, and test 8 is analyzed in order to get the relation between the different roughness's plates used in the experiment for slope equal to 1:600 (mild slope). From Figure 2, the roughness coefficients for each type of channel bed surface remain in small variation for different flow rate. Similarly, it shows the same outcome as the steep slope (1:900). The average and ranges of Manning roughness coefficient has presented in Table 3.

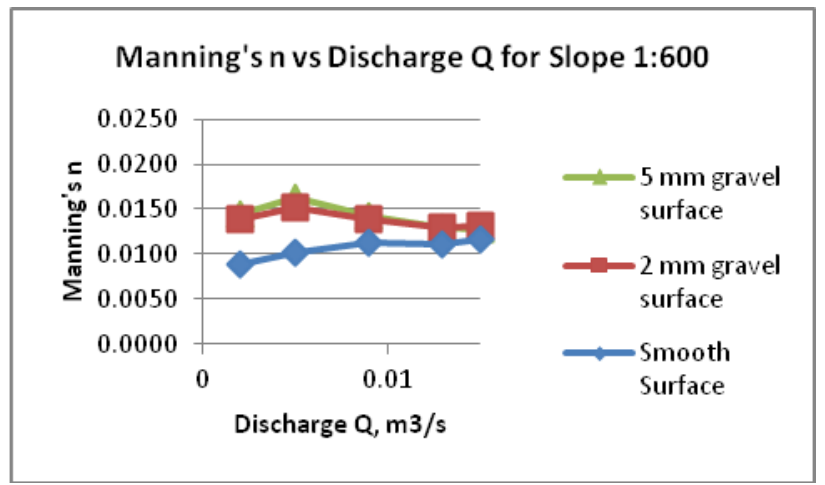

Figure 2: Manning's n versus Discharge Q for Slope 1:600

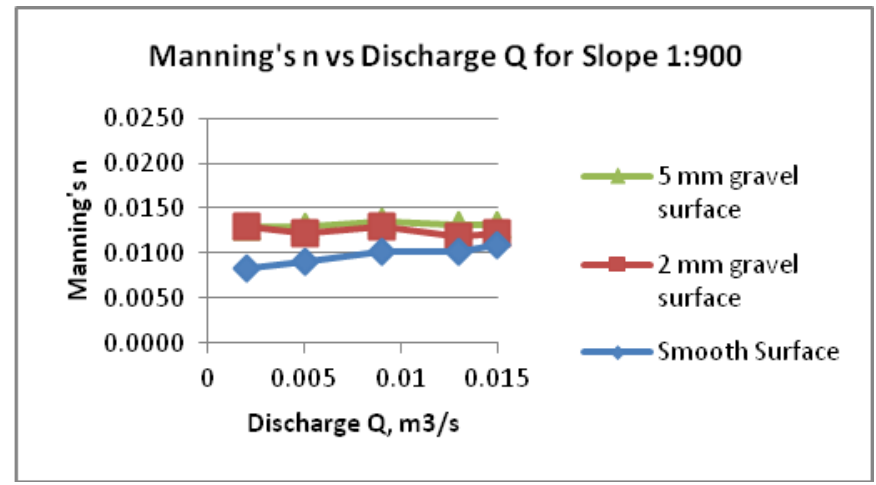

Figure 3: Manning's n vs Discharge Q for Slope 1:900

Table 3: Average Roughness Coefficient of Different Surface for Slope 1:600

\begin{tabular}{|c|c|c|c|c|c|c|c|}
\hline \multirow{2}{*}{ Bed Surface (Plate) } & \multicolumn{5}{|c|}{ Discharge Q $\left(\mathrm{m}^{3} / \mathrm{s}\right)$} & \multirow{2}{*}{ Average $\mathrm{n}$} & \multirow{2}{*}{ Range of $n$} \\
\hline & 0.002 & 0.005 & 0.009 & 0.013 & 0.015 & & \\
\hline Steel & 0.0089 & 0.0101 & 0.0113 & 0.0111 & 0.0117 & 0.0106 & $0.0089-0.0117$ \\
\hline $2 \mathrm{~mm}$ Grain size & 0.0138 & 0.0151 & 0.0139 & 0.0129 & 0.0128 & 0.0137 & $0.0128-0.0151$ \\
\hline $5 \mathrm{~mm}$ Grain size & 0.0145 & 0.0163 & 0.0142 & 0.0130 & 0.0131 & 0.0142 & $0.0130-0.0163$ \\
\hline
\end{tabular}

Test 3 (steel surface), Test 6 (2 mm grain size), and Test 9 (5 mm grain size) are analyzed to study the effect of bed material on roughness coefficient. In the same way, the result show almost identical characteristic compare to previous analysis. A graph of Manning's n versus flow rate Q for flat slope is constructed and plotted in Figure 3. Generally, the graph indicate almost constant Manning coefficient for the various flow rate for flat slope which is same to steep and mild slope.

In addition to the study, a table of average Manning coefficient for each bed surface for various discharge is shown in Table 4. From the table, the $5 \mathrm{~mm}$ grain size appears to be the highest roughness coefficient compare to others and it explain the higher resistant yielded by the rough surface which comply with Manning equation.

Table 4: Average Roughness Coefficient of Different Surface for Slope 1:900

\begin{tabular}{|c|c|c|c|c|c|c|c|}
\hline \multirow[t]{2}{*}{ Bed Surface (Plate) } & \multicolumn{5}{|c|}{ Discharge Q $\left(\mathrm{m}^{3} / \mathrm{s}\right)$} & \multirow{2}{*}{ Average $\mathrm{n}$} & \multirow{2}{*}{ Range of $n$} \\
\hline & 0.002 & 0.005 & 0.009 & 0.013 & 0.015 & & \\
\hline Steel & 0.0083 & 0.0091 & 0.0101 & 0.0101 & 0.0110 & 0.0097 & $0.0083-0.0110$ \\
\hline $2 \mathrm{~mm}$ Grain size & 0.0130 & 0.0122 & 0.0130 & 0.0119 & 0.0121 & 0.0124 & $0.0119-0.0130$ \\
\hline $5 \mathrm{~mm}$ Grain size & 0.0130 & 0.0129 & 0.0135 & 0.0132 & 0.0131 & 0.0131 & $0.0129-0.0135$ \\
\hline
\end{tabular}

\subsection{Effect of roughness on discharge}

Table 5 shows flow rate, Q according to the fixed roughness coefficient and slopes. Test 1 (1:300) produce the highest flow rate $\left(0.0249 \mathrm{~m}^{3} / \mathrm{s}\right)$ since it has the lower roughness coefficient comparing to the other two test of equal slope. Test 9 shows the lowest flow rate of equal slope which is $0.0151 \mathrm{~m}^{3} / \mathrm{s}$ since it has a higher roughness coefficient among the slope 1:900. The Manning theory stated that the flow rate is inversely proportional to the roughness coefficients. So, the channel flow rate decreases as the Manning's $n$ increases. From the experiments, it concluded that the roughness will affect the flow rate of channel. Roughness represents the flow resistant in a channel. So, when the flow resistance increases as roughness 
coefficient increases, it produces a retarding force on the water. Thus results lower value in flow rate. Graph of discharge, $\mathrm{Q}$ versus Manning's n was plotted as Figure 4.

Table 5: Water Discharge of Different Bed Roughness for Specific Slope with Hydraulic Parameters

\begin{tabular}{|c|c|c|c|c|c|c|c|c|c|c|}
\hline$\frac{\frac{0}{0}}{\sqrt{n}}$ & $\stackrel{\vec{\omega}}{\oplus}$ & 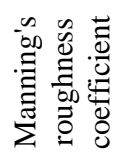 & $\Xi$ & 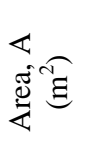 & $\widehat{\overparen{\Xi}}$ & $\underset{\simeq ્}{\overparen{\Xi}}$ & 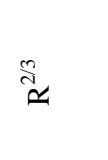 & $\sim$ & $\stackrel{n}{\mathrm{~N}}$ & 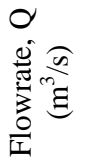 \\
\hline \multirow{3}{*}{$1: 300$} & 1 & 0.0137 & 72.99 & 0.036 & 0.54 & 0.0667 & 0.1644 & 0.00333 & 0.0577 & 0.0249 \\
\hline & 2 & 0.0177 & 56.50 & 0.036 & 0.54 & 0.0667 & 0.1644 & 0.00333 & 0.0577 & 0.0193 \\
\hline & 3 & 0.0191 & 52.36 & 0.036 & 0.54 & 0.0667 & 0.1644 & 0.00333 & 0.0577 & 0.0179 \\
\hline \multirow{3}{*}{$1: 600$} & 4 & 0.0106 & 94.33 & 0.036 & 0.54 & 0.0667 & 0.1644 & 0.00167 & 0.0408 & 0.0228 \\
\hline & 5 & 0.0137 & 72.99 & 0.036 & 0.54 & 0.0667 & 0.1644 & 0.00167 & 0.0408 & 0.0176 \\
\hline & 6 & 0.0142 & 70.42 & 0.036 & 0.54 & 0.0667 & 0.1644 & 0.00167 & 0.0408 & 0.0170 \\
\hline \multirow{3}{*}{ 1:900 } & 7 & 0.0097 & 103.9 & 0.036 & 0.54 & 0.0667 & 0.1644 & 0.00111 & 0.0333 & 0.0203 \\
\hline & 8 & 0.0124 & 80.65 & 0.036 & 0.54 & 0.0667 & 0.1644 & 0.00111 & 0.0333 & 0.0159 \\
\hline & 9 & 0.0131 & 76.34 & 0.036 & 0.54 & 0.0667 & 0.1644 & 0.00111 & 0.0333 & 0.0151 \\
\hline
\end{tabular}

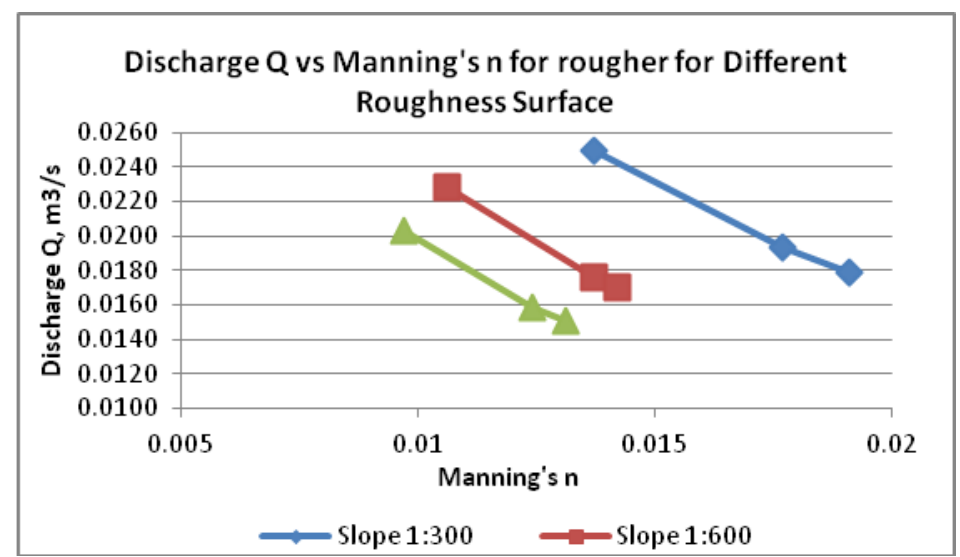

Figure 4: Discharge Q Versus Manning's n of Different Roughness Surface for Different Slope

\subsection{Effect of Slope on Roughness Coefficient}

The results of test 1 , test 4 , and test 7 were compared to study the effect of slope on roughness for smooth surface and the results of the smooth surface are plotted in Figure 5.

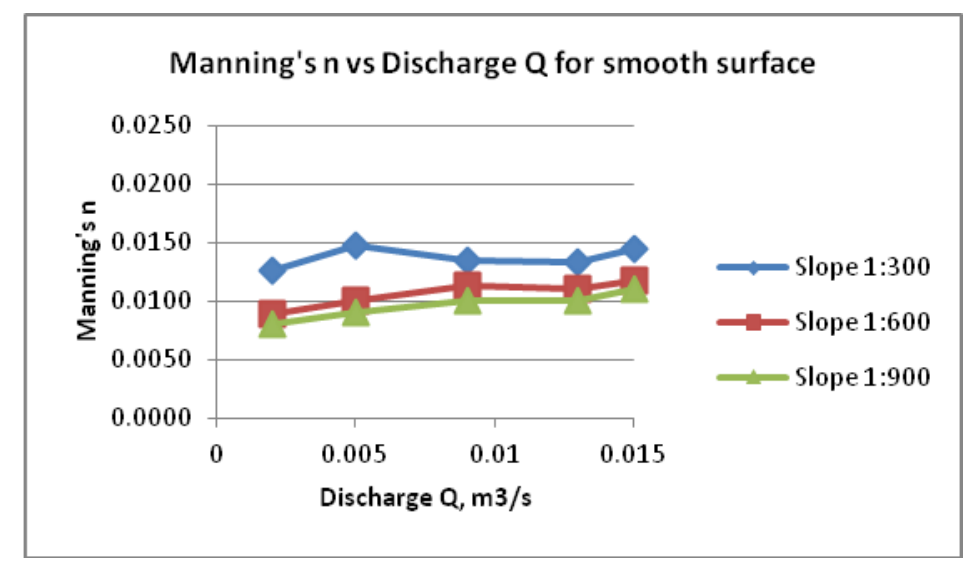

Figure 5: Manning's n versus Discharge Q for smooth surface

As shown in the Figure 5, the values of Manning's $n$ are decreasing from steeper to flatter which act in accordance with the Manning's theory [3]. So, the roughness coefficient for channel slope equal to 1:300 is higher comparing with channel slope of 1:600 and 1:900. Besides that, it was observed that the influence of Manning roughness coefficient decreases when come to a flatter slope (1:900). From Figure 5, the decrease trend is not constant as the different of Manning's $\mathrm{n}$ between the slope $1: 300$ and $1: 600$ for discharge $0.002 \mathrm{~m}^{3} / \mathrm{s}$ is 0.0055 while the different of Manning's $\mathrm{n}$ between the slope 1:600 and 1:900 for discharge $0.002 \mathrm{~m}^{3} / \mathrm{s}$ is only 0.0009 . In summary, it may be concluded that the effect of channel slope on roughness is decreasing gradually for flatter slope. 
Similarly, results with grains size of $2 \mathrm{~mm}$, and $5 \mathrm{~mm}$ were analyzed and plotted into graph as shown in Figures 6 and 7. The results of test 2, test 5 , and test 8 were used to study effect of slope on roughness coefficient for grains size of $2 \mathrm{~mm}$ while test 3 , test 6 , and test 9 used to examine impact of slope on roughness coefficient for 5 mm grain size. As conclusion, the effect of channel slope on roughness is decreasing gradually when the slope channel is decreasing which is similar to the smooth and rough surface conditions.

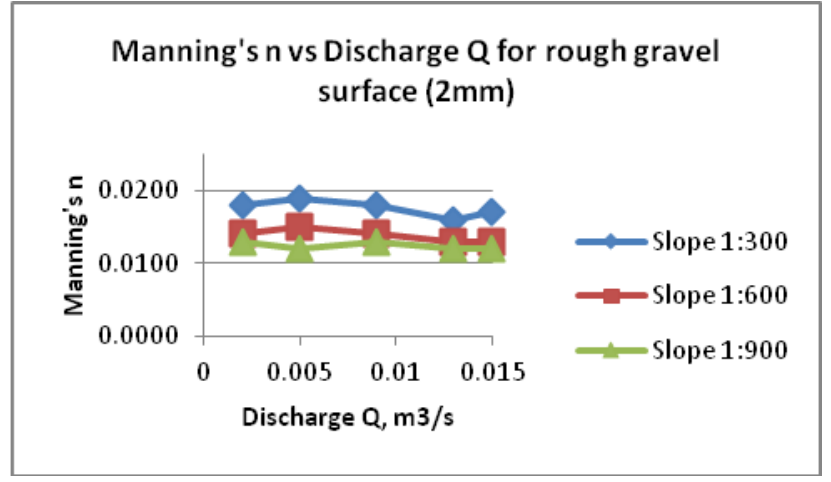

Figure 6: Manning's n versus Discharge Q for $2 \mathrm{~mm}$ grain size

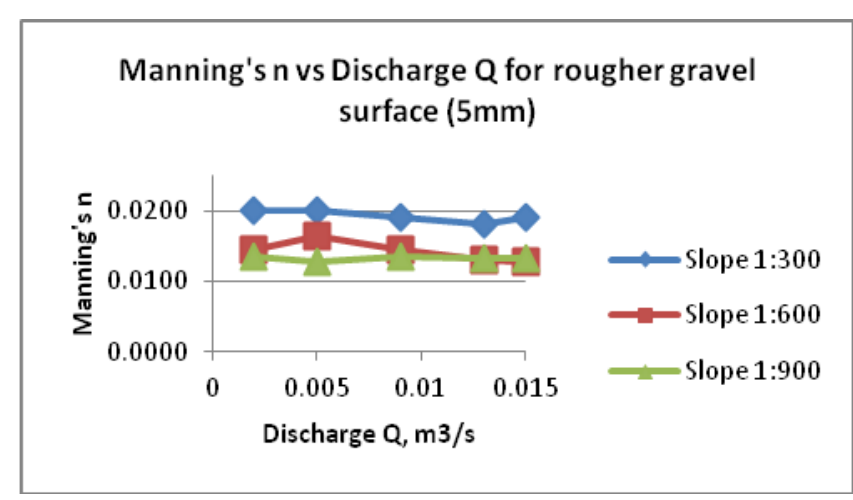

Figure 7: Manning's n versus Discharge Q for $5 \mathrm{~mm}$ grain size

\section{CONCLUSIONS}

Several conclusions is made; $i$. The discharge increases as the roughness coefficient decrease for a given slope and channel bed surface. ii. Channel slope and surface roughness appears to be the main factor in determining the roughness coefficient. iii. For a given surface roughness, increase in flow rate does not have significant effect on roughness coefficient. iv. For a given surface roughness, roughness coefficient increases as slope increases. But the rate of increase is not a linearly proportional to increase in slope. v. A material with uneven or irregular surface increase the roughness coefficient. vi. Larger grain size gravel having higher roughness coefficient.

\section{REFERENCES}

[1] H.R. French, "Hydraulic of Open Channel Flow", Washington: McGraw-Hill, 176-178,1966.

[2] F. Huthoff, and D. Augustijin, "Channel roughness in 1D steady uniform flow: Manning or Chezy", Research for Managing Rivers: Present and Future Issues, 98-100, 2005.

[3] V.T. Chow, “Open Channel Flow,” London: McGRAW-HILL, 11,95,99,136-140,1959.

[4] L.D. Donker, P. Troch, R. Verhoeven, K. Bal, P. Meire, and J. Quintelier, "Determination of the Manning Roughness Coefficient Influenced by Vegetation in the River", Environ Fluid Mech (2009) 9:549-567, 2009.

[5] B.C. Yen, "Open Channel Flow Resistance", Journal of Hydraulic Engineering 128 (1): 20 - 39, 2002. 